Stéphane Bellon

Servane Penvern Editors

Organic Farming,

Prototype for

Sustainable

Agricultures

$\underline{\underline{W}}$ Springer 


\title{
Chapter 14 \\ The Freedoms and Capabilities of Farm Animals: How Can Organic Husbandry Fulfill Them?
}

\author{
Jacques Cabaret, Caroline Chylinski and Mette Vaarst
}

\begin{abstract}
Organic farming promotes animal husbandry practices that consider the welfare of the animals on the farm. The concept of animal welfare and the standards that should encompass this concept have in many cases been largely generalised in practice, which leaves relevant aspects of animal freedom or capabilities insufficiently addressed. This chapter puts forth the prospect that the capabilities approach offers an appropriate practical platform by which to improve welfare in farm animals by meeting a wider range of their natural needs and abilities. The capabilities approach coupled with effective health planning could foster organic husbandry towards a more acceptable production system for farmers and consumers alike.
\end{abstract}

Keywords Welfare $\cdot$ Animal liberty $\cdot$ Animal capabilities $\cdot$ Organic husbandry

\subsection{Introduction}

Animal welfare is a much debated, and often highly emotive topic. Many different views can be taken when considering how to best provide our animals with ethically-just living conditions to meet their needs. In some ways, it is our immediate sympathy and compassion for nonhuman animals that has driven the notion of creating just relations between humans and animals, and ensuring that animals live lives that are worth living from their own perspective. On the other hand, we cannot rely on sympathy alone to bring about conscientious change. With the increased industrialisation of farming, research and scientific facts are needed to support ethical

J. Cabaret $(\bowtie) \cdot$ C. Chylinski

INRA-Université de Tours, UMR1282 Infectiologie et Santé Publique, 37380 Nouzilly, France e-mail: jacques.cabaret@tours.inra.fr

J. Cabaret

Université Paris I-Sorbonne, 13 rue du Four, 75005 Paris, France

M. Vaarst

Department of Animal Science, Aarhus University, PO-Box 50, 8830 Tjele, Denmark

S. Bellon, S. Penvern (eds.), Organic Farming, Prototype for Sustainable Agricultures, 
decision-making. The aim of this chapter is to discuss the reality of animal welfare on organic farms today, as a function of evidence and knowledge.

Deepening our scientific knowledge of animal welfare provides greater support for the deserved moral status of the animals. Several practical methods for assessing animal welfare have already been developed and implemented in the field (see Veissier et al. 2012). It is beyond the scope of this chapter to discuss them in detail. Instead, this chapter evaluates the extent to which current organic principles, as proposed by the IFOAM (International Federation of Organic Movements 2012), meet the animal welfare standards as laid out in two different concepts, the five freedoms and the capabilities of animals.

\subsection{The Five Freedoms: Ideal States for Welfare?}

The five freedoms were developed to account for both the physical and psychological well-being of the animal which, taken together, define animal welfare. These were proposed as 'ideal states' to work towards rather than standards of acceptable (minimum) levels of welfare. They were intended to provide a framework for welfare analysis for animals on the farm, in transit, at market or at the place of slaughter (Farm animal Welfare Council: fawc.org accessed 03/04/12). The five freedoms include:

1. Freedom from Hunger and Thirst - by sufficient access to fresh water and a diet to maintain full health and vigour.

2. Freedom from Discomfort-by providing an appropriate environment including shelter and a comfortable resting area.

3. Freedom from Pain, Injury or Disease — by health promotion, disease prevention and relevant immediate intervention in the event of any condition that causes pain, injury or disease.

4. Freedom to Express Normal Behaviour-by providing sufficient space, proper facilities and company of the animal's own kind.

5. Freedom from Fear and Distress - by ensuring conditions and handling that minimise mental or emotional suffering.

Certain elements of the five freedoms may be at odds with organic animal husbandry. Firstly, the five freedoms most likely challenge the cultural values or personal opinions of the farmer or their respective society (Tague 2010). Farmers values concerning nature (Kaltoft 1999) are particularly important as they translate into choices made in husbandry (i.e., whether to be an organic producer, whether to sell their products directly to consumers or not). Secondly, fulfilling the five freedoms may not be conducive to the most economically profitable options in the short term. And lastly, the five freedoms may present a conflict of interest within the organic system itself. For example, under European organic legislation, the use of chemical substances is limited, with one exception, anthelmintics. However, the same legislation further states that responsible action should be taken to prevent animal suffering in 
cases of disease where the use of efficient drugs is then recommended. Yet, according to American organic legislation, the animals cannot be sold as organic if they have been treated with antibiotics, which thereby discourages the use of medical treatment and instead encourages health promotion on a very radical level. It is paramount that animals that require treatment should receive it in a qualified way. It is also important that animals are not only treated for disease alone, but that better health is also promoted, e.g., through supportive feed, adequate rest and comfort, etc. Efforts to minimise antibiotics should be based solely on the promotion of animal health and welfare to thereby remove the need for treatment. Research has shown that regulations and goals focusing on minimising antibiotic treatment can support the emphasis on health and welfare promotion (Ivemeyer et al. 2012; Bennedsgaard et al. 2010), which will also minimise the risk of suffering. This will be discussed below.

\subsection{Organic Agriculture Principles in Relation to Welfare}

Organic agriculture is based on four principles (IFOAM 2012): health, ecology, fairness and care.

Health is the wholeness and integrity of living systems. It is not simply the absence of illness, but the maintenance of physical, mental, social and ecological well-being. Immunity, resilience and regeneration are key characteristics of health. Organic agriculture should avoid the use of fertilisers, pesticides, animal drugs and food additives that may have adverse health effects.

This health principle is directly linked to the five freedoms, especially the freedoms of avoiding pain, suffering, disease, and discomfort: it is at all times important to keep the animal in a healthy state that enables it to resist diseases and be supported mentally, emotionally and physically.

The principle of ecology emphasizes that 'Organic Agriculture should be based on living ecological systems and cycles, to work with them, to emulate them and to help to sustain them'. Animals are part of farming systems and they should contribute to a well-balanced system where feed and manure circulate, and where space and production is in harmony with what the soil and the rest of the farm can produce in a way that is sustainable from an environmental, social, institutional and economic point of view.

The principle of fairness promotes a type of agriculture that is built on 'relationships that ensure fairness with regards to the common environment and life opportunities'. This principle stresses that animals should be provided with the conditions and opportunities of life that accord with their physiology, natural behaviour and well-being. This means that the animal should not be pushed to exceed its capabilities in any way, physically, physiologically, mentally or emotionally. It emphasizes the need to ensure that the animals are given an environment in which they can live in dignity and in accordance with their needs. An example to illustrate a lack of fairness is the farming of bees, which are maintained in difficult monocultural 
landscapes, with minimal flowering plants for a relatively short period, thus pushing the bees to exceed their physical and physiological capabilities.

The principle of care stipulates that 'Organic Agriculture should be managed in a responsible manner to protect the health and well-being of current and future generations and the environment'. It also directs us to not bring animals into life situations that cannot be adequately managed. This principle may describe most directly the human role towards organic animals. It addresses the responsibility of the farmers and of those who take responsibility for animals, to provide a care system that allows the animals to live their lives as close to their respective 'nature' as possible. This refers to the animals' ability to perform natural behaviours, to access food that meets their physiological needs and in all ways, to be the animals that nature intended, as far as can be done under farming conditions. Achieving this principle relies upon human understanding of the animals and their natural needs, as well as sound judgment on when human intervention is necessary and what the appropriate measures to employ would be (Vaarst and Alroe 2012). This requires skill, knowledge and careful observation. It is important to stress that in the case of disease, relevant action can include the provision of special care and support as well as administration of the necessary and appropriate treatment. Lund et al. (2004) described this as a mutual ethical contract between human (care) and animal (production), which eventually comes to an unavoidable 'natural end' at slaughter.

The human responsibility to manage animals well and to ensure their health and welfare can incorporate expertise from varying points of view. Science can play an effective and supportive role in making ethical judgements. In turn, this can influence the future development of organic livestock farming to continuously strive towards improved standards of animal health, consumer safety and ecological and environmental sustainability. Yet, these ethical decisions cannot be made on the basis of science alone. Valuable solutions can also be found in the accumulated wisdom of farmers, agricultural workers and veterinarians, as well as in traditions and indigenous knowledge tested and experienced over time. For the animals to benefit from this combined knowledge, continual exchange and development is necessary. Theoretically, the implementation of these four principles should indirectly ensure that the five freedoms are met. Animal welfare and the ethics of organic husbandry have been described (Verhoog et al. 2004) and discussed at length in numerous articles and books. However, many of these have also referred to elements of discord that can arise from applying ethical approaches to everyday farming, often resulting in compromises. Porcher (2014, in this book) highlighted the difficulty that many farmers have in maintaining their organic standards:

This applies mainly to the transport and slaughtering of animals, the choice of breeds, the specifications and, more broadly, the utilitarian and economic paradigm underlying organic animal husbandry.

Porcher expresses her concern that the animals, as sentient beings, have become the forgotten partners in the contract of organic agriculture. Thus, although the ideals of organic animal welfare and the ideals of the five freedoms first appear aligned, the application and guidance provided by these two 'sets of principles' cannot be expected to - in any way_-be a guarantee for good animal welfare. 
Welfare limitations can be viewed in the light of animal rights. We will thereby explore to what extent animal rights are covered in the five freedoms, and if they are met in an organic animal husbandry. We will also examine how the five freedoms hold up in relation to the capabilities approach, a concept that goes beyond basic survival to characterise those aspects required to attain a 'quality of life' as initially described for humans by Sen (2005), and others. To note, we assume that the freedoms relating to 'no hunger or thirst' and 'provide shelter and a comfortable resting area' are such evident basic needs that we do not pay specific attention to them.

\subsection{Animal Rights and Welfare}

The rationale behind animal welfare stems from findings that animals are sentient beings, with the ability to experience both pleasure and pain. This broke with the previously held view that humans were above animals and, therefore, have special inherent 'rights' (speciesism). When all human and nonhuman animals are capable of suffering, all should be worthy of equal consideration and rights. A central argument in Singer's book, 'Animal Liberation', published in 1975, is an expansion of the utilitarian idea in that "the greatest good of the greatest number" is the only measure of welfare and, therefore, the only valid guide to ethical behaviour. Although Singer belonged to the movement that promoted humaneness and respect for animal life and welfare, he does not raise specific concern about eating animals or using animals for work, insofar as they are raised and killed in a way that does not involve fear, pain and suffering. Animal rights defenders are less focused on this perspective, but rather more so on a complete ban of the use of animals altogether (see Jeangène Vilmer (2008) for the detailed position of Regan or Francoine).

\subsection{Freedoms in Relation to 'Animals' Capabilities'}

It is our opinion that the five freedoms should not be the sole matrix upon which animal welfare is based and analysed. Having originally been defined and intended as guidelines, they may be subject to substantial interpretation among the various care providers (from farmers to vets). We propose examining animal welfare in light of the 'capabilities approach' as outlined by Nussbaum (2001). This approach emphasizes the fact that animals have a moral status as defined by Warren in 1997:

To have moral status is to be morally considerable, or to have moral standing. It is to be an entity toward which moral agents have, or can have, moral obligations. If an entity has moral status, then we may not treat it in just any way we please; we are morally obliged to give weight in our deliberations to its needs, interests, or well-being". Although Nussbaum's approach was originally designed to capture the liberties that encompass a 'quality of life' in humans (Sen 2005), they have since been adapted to animals. Anand and coauthors (2005) stated: "Sen defines capabilities as what people are able to do or able to be - the opportunity they have to achieve various lifestyles and as a result, the ability to 
live a good life. He differentiates this from what he calls functionings - the things a person actually does and experiences. Functionings in humans may vary from the elementary, such as being adequately nourished and being free from avoidable disease, to complex activities or personal states, such as taking part in the life of the community and having self-respect.

This approach contributes towards understanding the relationship between an animal's inherent nature (what they are able to do or to be) and suitable welfare. We find that this capabilities approach adds another dimension to the issue of welfare by presenting interesting and relevant perspectives that, in addition, have the merit of being applicable to organic animal husbandry situations. The 10 capabilities proposed by Nussbaum (2001) for animals are specified and discussed below.

1. Life. Being able to live to the end of a life of normal length; not dying prematurely, or before one's life is so reduced that it is not worth living.

2. Bodily Health. Being able to have good health, including reproductive health; to be adequately nourished; to have adequate shelter.

3. Bodily Integrity. Being able to move freely from place to place; to be secure against violent assault, including sexual assault and domestic violence; having opportunities for sexual satisfaction and reproductive choices.

4. Senses, Imagination, and Thought. Being able to have an adequate education. Being able to have pleasurable experiences and to avoid non-beneficial pain.

5. Emotions. Being able to attach to things and people outside ourselves; to love those who love and care for us, to grieve at their absence; in general, to love, to grieve, to experience longing, gratitude, and justified anger. Not having one's emotional development blighted by fear and anxiety.

6. Practical Reason. Being able to plan one's life. Nussbaum (2001) discussed that this is not easily applicable for farm animals, although some animals may be engaged in "projects".

7. Affiliation. Being able to live with others, to engage in various forms of social interaction.

8. Other Species. Being able to live in relation to animals, plants, and the world of nature.

9. Play. Being able to play.

10. Control Over One's Environment. Being able to hold "property" (for example, a place to sleep or to be milked).

The extent to which these capabilities can be applied to welfare under organic animal husbandry conditions will now be discussed in relation to those of conventional farms.

\subsection{A First Set of Capabilities in Organic Animal Husbandry: Life, Bodily Health and Integrity}

We suggest that the three capabilities of 'life', 'bodily health' and 'integrity' relate directly to the five freedoms. We therefore choose to focus on them by considering the extent to which these capabilities can be applied to animal welfare under organic 
farming conditions. This will be discussed in relation to cases with free-range farms (as all organic farms are) and contrasted with conventional farms. These cases serve as examples to bring the discussion into a practical framework.

\subsubsection{Life}

Somewhat ironically, death is the measure by which the capability of life is measured. Although this is a crude evaluation of the capability and does not account for a reduced quality of life, it remains the best available indicator. Specifically, this relates to the age of animals at culling and mortality. A study by Benoit and Laignel (2009) comparing 25 conventional and nine organic grassland-based sheep production systems in the Centre region of France, provides a practical example of this. Lamb mortality rates were found to be 16.2 and $16.5 \%$ in conventional and organic farms, respectively, and ewe mortality rates were 5.9 and $5.3 \%$. The culling percentage was also very similar at 20.4 and $20.6 \%$. None of these variables were significantly different between the farms. A similar study that investigated 152 conventional and 22 organic beef cattle farms in the same area (Veysset et al. 2009) found slightly greater differences. The calf mortality rates were 6 and $7 \%$ for conventional and organic farms, respectively, whereas the culling rate was 20 and $23 \%$. A study in Wisconsin dairy herds did not show any difference in culling rates: 18 vs. $17.2 \%$ (Sato et al. 2005). A greater difference is seen among mono-gastric animals that are largely maintained indoors on conventional farms, but on pasture in organic farms. The mortality rate of organic piglets from birth to weaning is highly variable among European countries (Prunier 2010), ranging from 15\% in Italy to $35 \%$ in France. This range was smaller in Austria, Denmark, Germany and Sweden at $28-30 \%$. These figures are nearly $25 \%$ higher than those observed in conventional pig husbandry. Based on a five-year study in Western France, broiler chicken mortality was found to be 4,3 and $5 \%$ in organic, free-range and conventional husbandry, respectively. Mortality in laying hens is slightly higher in organic than in non-organic free-range farms, and is nearly double that observed in conventional production (Magdelaine 2006). The reasons for greater mortality in organic husbandry of mono-gastric animals may be related to how suitable the currently used breeds are, e.g., for outdoor production.

One of the greatest challenges to the life capability is the ending of life, namely how the animals are transported and slaughtered. No differences exist in these practices between organic and conventional management systems. Farmers become increasingly dissatisfied with these practices according to Porcher (2003) and she has consequently proposed, and tested, the concept of mobile abattoir facilities. The idea is to reduce stress associated with transport and waiting time before slaughter (Porcher and Daru 2005).

Irrespective of the welfare standards attained in relation to the methods of transport and slaughter, the death of the animal is somewhat difficult to tie into the capability of life described by Nussbaum (2001). Reconciling the death with the life capability is overcome by some cultures that transform the act of killing into a 
sacrifice as seen in the practices of Halal and Kosher. However, the validity of these arguments is under much debate. The human conscience can also accommodate the act of death by establishing strong dissociations between the animals and the slaughterhouse (farmers) or animals and the food (consumers).

\subsubsection{Bodily Health}

In both conventional and organic farms, the farmer is assumed to offer adequate food and shelter to his animals to meet the ethical expectations of consumers and citizens, and to meet legislative and market requirements (sanitary and organoleptic quality of the produced meat). On organic farms, the animals are fed with organic feed that, whenever possible, is local in origin and grown without pesticides or synthetic fertilisers that may interfere with the health status of the animals, although no data has confirmed this (Zollitsch et al. 2004). Rather surprisingly, Nussbaum (2001, 2006a, b) did not clearly identify diseases and appropriate disease control methods in relation to her bodily health capability. Instead, she assumed that if good conditions are provided for the animals, then disease will disappear or not appear at all. As a consequence of this, we chose to include animal health and welfare planning under bodily integrity in our attempt to loyally follow the capability approach of Nussbaum.

Health is much more than the mere 'absence of disease', and adequate health promotion practices can improve the overall health of the animals through access to fresh air, exercise, high quality feed and clean water. The maintenance of good health clearly includes disease prevention practices and strategies such as the use of drying-off to prevent mastitis in dairy cows. It also comprises immediate and relevant intervention where there are signs of disease. Clearly, organic animal husbandry operates under a 'health promotion and disease prevention is better than cure' ideal, and attempts are made where possible to avoid dependency on veterinary medicinal inputs, including vaccines, through adapted management practices. The use of vaccines is considered acceptable as long as the animals on a particular farm are at high risk of a particular disease. Organic broilers and laying hens are a good example of the intensive use of vaccinations, mostly against viral diseases. A survey in Sweden showed that the 56 laying hen farms vaccinated against Marek's disease, infectious bronchitis, avian encephalitis and coccidiosis (Berg 2001). In Switzerland, the following protocol recommended by the FIBL (Research Institute of Organic Agriculture) is applied for organic laying hens at different ages: day 1: Marek's disease; day 9: coccidiosis (eight coccidia species); week 3: Gomboro disease; week 5: infectious bronchitis; week 7: Gomboro disease; week 9: infectious bronchitis; week 12: avian encephalitis: week 15: infectious bronchitis. The vaccination protocols in organic and conventional poultry herds remain largely similar.

According to the current organic EU regulation, alternative medicines with demonstrated efficacy should be selected over allopathic medicine. The complementary and alternative medicines (CAM) are a group of diverse medical and health 
care systems, practices and products, most of which are not considered as a part of biomedicine ('conventional medicine'/'school medicine'). Phytotherapy and homoeopathy are among the most commonly used alternative medicines in organic husbandry. Cabaret (1986) described the use of phytotherapy in organic and, to a lesser extent, conventional farms, and Vaarst et al. (2004) described the use of homeopathy in organic herds. The efficacy of these therapeutics is often difficult to assess using natural scientific methods, and only a few randomised controlled trials have been done (Wynn and Wolpe 2005). Veterinarians have a moral and ethical obligation to provide therapies with proven or experienced efficacy, and they have the obligation to respect the farmer's wishes and beliefs (Wynn and Wolpe 2005). Vaarst and co-authors (2004) stated that:

\section{It has been suggested that the restriction on medicine use may lead to unnecessary suffer- ing if animals are left without treatment. This appears to be a general concern within the veterinary profession....avoidance of suffering clearly overrules any limits on the use of medicine.}

The choice of treatment and the type of medicine selected will often be the result of a compromise between the farmer's wishes versus those of the veterinarians (Cabaret et al. 2012). In any case, it is important to give the animal the sufficient care, attention and support, no matter which treatment it has received. Disease patterns in conventional and organic farms do not appear to be very different and, indeed, it has been shown that the difference between herds within each production system are bigger than a systematic difference between organic and conventional (Thamsborg et al. 2004; Cabaret et al. 2012). This highlights the importance of management and husbandry choices on a farm level.

Organic husbandry practices could be improved through animal health and welfare planning programmes (Hovi et al. 2004; Vaarst et al. 2012). These programmes supplement the Nussbaum capabilities, which remain limited in the area of disease. The health plans can be directed at acute problem-solving, goal-oriented efforts to avoid particular diseases, or long-term health planning, based on the farmer's goals for the herd or flock. An example of these planning programmes can be seen in the Farmer Field Schools, a concept for learning, knowledge exchange and empowerment that is being developed and used in some countries. In Denmark, the concept has been adapted to Danish conditions and is referred to as 'Stable Schools'. The first four Stable Schools were established in 2004 with the aim of phasing out the use of antibiotics in Danish organic dairy herds (Vaarst et al. 2007). In Germany, the same approach was adapted and the first results seem very promising (Brinkmann et al. 2012). In Stable Schools, problems are identified and solutions proposed based on the farmer's individual wishes and goals for the farm. The successful implementation of a plan combines the farmers' knowledge with facts about actual events and conditions in the herd. This information is collected in a systematic way and the views of external persons such as other farmers or health advisors (Vaarst et al. 2012). The European CORE-organic project ANIPLAN highlighted a number of principles that are important when creating lasting changes on a farm (see Box 14.1 below) (Nicholas and Vaarst 2011). This project aimed to develop a 
Fig. 14.1 Representation of animal health and welfare planning as a continuous process based on assessment $(A)$, planning $(H P)$ and evaluation $(E)$

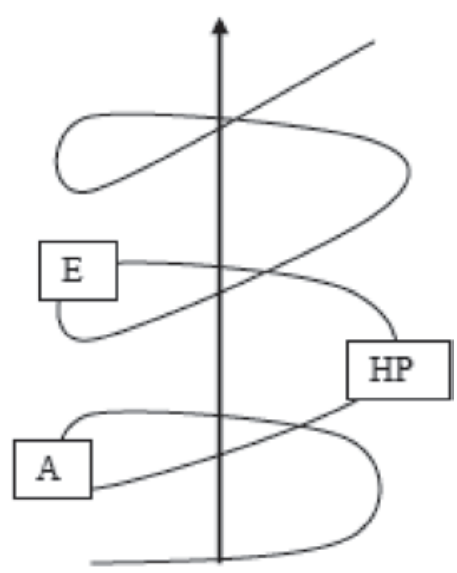

model for animal health and welfare planning that can be implemented in different types of farming environments, e. g., large-scale dairy husbandry as well as alpine, smallholder and diverse farming systems. The principles were developed through discussion, which catalyses this process and which is necessary in order to achieve a balance between farmers' needs, animals' needs and the wider societal perception of health and welfare. At the same time, the multiple objectives of organic animal husbandry should also be fulfilled. The first of the key principles is illustrated in Fig. 14.1 and focuses on how animal health and welfare planning should be seen as a continuous process.

Box 14.1. The nine principles characterised by the European COREorganic project ANIPLAN as a good and appropriate animal health and welfare planning process.

1. A health planning process should aim at continuous development and improvement and should incorporate the promotion of health and disease handling based on a strategy that incorporates (as described in Fig. 14.1 above) a learning cycle among the involved persons, including: assessing the situation, evaluating, taking action and reviewing the development, etc.

2. Farm specific: all planning should be based on the specific farm.

3. Farmer ownership: the farmer should lead the way, and not the advisor.

4. External person(s) should be involved: planning should be based on dialogue between the owner and somebody seeing the situation from the outside.

5. External knowledge: the knowledge that provides background for decisions should be partly based on an outside 'view of the farm', including its data, seen by somebody else). 
6. Organic principles framework (systems approach): the organic principles should always guide planning on an organic farm, which implies taking a systems approach.

7. Written: common memory is necessary; written minutes are crucial and should be based on what the farmer commits him/herself to do, and not recommendations alone.

8. Acknowledge good aspects: don't just focus on problem areas, but also remember to include a description of positive developments.

9. Involve all relevant persons in the process: all those with responsibilities and tasks to do within the herd should be involved in the process to ensure the exchange of knowledge and common understanding, as well as joint action.

The Danish Stable Schools demonstrated that farmer groups that shared a common goal to phase out antibiotic use were able to decrease antibiotic use by $50 \%$ in one year with no negative side effects in terms of disease or production (Bennedsgaard et al. 2010). One major factor for this was the focus on the promotion of health and welfare rather than disease handling in terms of disease prevention and disease treatment.

\subsubsection{Bodily Integrity}

The ability of animals to freely move from place to place is limited in both organic and conventional livestock systems. This capability remains unfulfilled for conventional animals reared intensively indoors, which is the case for the vast majority of pig and poultry husbandry practices. Many pasture management choices to optimise herbage production, such as combining grazing and hay making, may restrict the opportunities for animals to graze and move freely on pasture. In Europe, there are only a few extensive animal husbandry systems that permit a greater freedom of movement for the animals, and they are more common in organic than conventional practices. The bodily integrity capability encompasses sexual and other types of violence, which often differs only very slightly between organic and conventional livestock production. Some organisations and researchers have debated the issues surrounding the value of natural reproduction versus artificial insemination (Piccardi et al. 2011), although the choice will always be made by the farmers in the end. The genetic selection of animals has been developed over many years and much progress has been made through artificial insemination and breeding programs in the different breed registries, often with the focus on maximising production. Organic animal husbandry may be more inclined to include different breeding objectives.

Regardless of species, the primary breeding objectives for organic farming are likely to include disease resistance and longevity. Another area of importance is increased reliance 
on forage in ruminant diets. Good mothering abilities are also an important selection criterion in pigs and sheep. (Pryce et al. 2004)

These breeding objectives are achieved by means of a selection index, but in organic systems, the task may be complicated by the multiplicity of goals to be achieved and the relatively low number of animals involved in the production. The maintenance of genetic diversity, which may be of interest in organic animal husbandry, is difficult to cultivate in a selection index. Selective breeding means that the animals will not have any reproductive freedom, and the use of artificial insemination will preclude any sexual satisfaction. In that case, the 'animal capability' can be said to be restricted in organic as well as in conventional systems. Cross-breeding is justified by the increase in productivity through the heterosis phenomenon, and the F1 generation resulting from the two breeds or two lines are used both in conventional and organic pig and bird breeding. In that case, not only is the sexual capability of the animals impaired but, in addition, the farmers themselves are not the ones to make the decisions regarding reproduction. They fully rely on breeding companies to obtain hybrid lines, and this accounts for the near totality of poultry farmers, conventional as well as organic (Guéméné et al. 2009). To restore "genetic" independence, the farmers would have to turn to local breeds that are adapted to the specific environmental conditions in which they are reared, or to kin-selection on the farm.

Additional dilemmas exist regarding the bodily integrity of animals in both conventional and organic systems (Menke et al. 2004). For example, mulching (the removal of skin near the lambs' anus without any anaesthesia) is a practice widely used in Australian sheep to protect them against highly detrimental fly strike that may result in death following long periods of suffering. In this instance, the farmers largely perceive the ends (prevention of fly strikes) to justify the means (suffering during the rapid operation). Furthermore, they estimate that the use of anaesthetics would only serve to slow down the total operation time since it is performed on thousands of animals at a time. A similar situation exists for the castration of piglets, which has been widely practiced in organic as well as in conventional systems to prevent the undesirable odour ('boar smell') of the meat (banned by EU regulations as of 2015). This too is practiced without anaesthesia for time-saving reasons. The nose-ringing of sows is another issue. It is carried out to prevent rooting, a natural behaviour for pigs, but destructive to pastures and, hence, environmentally damaging, especially in large farms. No agreement has been reached on whether it should be allowed within the EU. It is currently banned in Sweden and the UK, but permitted in Denmark. Reaching an agreement on these issues is complicated by other concerns such as environmental pollution to accommodate the needs of animals and their welfare, which contradicts the principles of organic husbandry all together. Another example of this reverse husbandry is the practice of beak trimming in poultry. Intended to reduce feather pecking between individuals, this behaviour is only the result of high animal stocking densities. Thus, it is carried out to enable greater stocking densities, not for the benefit of the birds. This practice is prohibited in organic poultry farming and is therefore more respectful of animal welfare. 


\subsection{A Second Set of Capabilities in Organic Animal Husbandry: A Social Life with Emotions}

We include the following capabilities here: relating to members of their own species, as well as the senses and imagination, emotions and play. These capabilities largely correspond to the freedom to express normal behaviour and as such, they can be viewed as a key to attaining a life of quality.

\subsubsection{To Live in Relation with Other Species in Nature}

This means that animals will have access to the external world and that they will not be confined in buildings except under special circumstances. This meets consumers' expectations and is generally found in organic herds. Much has been proposed and debated on how species-specific behaviour can be maintained, mostly based on observations of wild groups (Waiblinger et al. 2004). Most data focus on social structure within a flock or herd, e.g., on intra-species interactions. There is a lack of knowledge about relationships with other species, except with humans (Waiblinger et al. 2006). These relationships need to be established between humans and each of the animals, and therefore require a certain number of humans per number of animals. The organic principles for animal husbandry emphasizes a framework that allows a life with 'naturalness' as much as possible, and human care and intervention whenever necessary. If this condition is fulfilled, sufficient human involvement will be ensured and will necessitate more people in larger farms.

In some countries, interactions between different animal species are frequent in organic husbandry. This may include mixed grazing to maximise grass production or to reduce internal parasitism (from the tropics (Giudici et al. 1999) to the subarctic (Sormunen-Cristian et al. 2008)). The potential benefits of inter-species interactions on welfare have not yet been studied although their impact on farm pathocoenosis (pathogen dynamics) has been suggested (Nicourt and Cabaret 2014, Chap. 9). The interaction of wild animals has not been studied either, or if so, only from the negative viewpoint of predation, particularly in free-range and organic poultry. These multispecies interactions are part of natural life and as such, add 'naturalness' to the animals' lives and may even alter the range of pathogens on a farm.

\subsubsection{To Experience Education and Emotions}

Play and social interaction is an important element in animal life. Play among piglets, for example, begins within the first few days after birth, peaking between 2 and 6 weeks of age (Waiblinger et al. 2004). Social models have been shown to play an important role in the behaviour and diet selection of young animals (Thorhalsdottir et al. 1987). They serve to enhance learning efficiency by reducing the need for ani- 
mals to rediscover foraging information through trial and error. Such learning may be transmitted from the experienced mother to the offspring. Studies have shown that lambs guided by their mothers were able to distinguish between different species of grass and legumes that were either safe or toxic to consume (Ginane and Dumont 2011). Orphaned lambs were unable to do the same. Studies have also shown that there is a transmission of self-medicative behaviour from mother to offspring (Sanga et al. 2011). The transmission of information from one generation to another in non-human animals relies on the memorisation of multi-sensorial cues (Nowak et al. 2011). Very early weaning will thus interrupt the mother-offspring relationship and reduce the share of education and emotions it provides. The cognitive abilities of animals have been substantially overlooked, but an increasing number of studies are showing that farm animals can perform 'executive' cognitive tasks that have typically only been equated with primate intelligence (Morton and Avanzo 2011). This 'executive' function refers to the ability to react adaptively: to learn associations between stimuli, actions and outcomes, and to then adapt their behaviour to changes in the environment. Such skills would be necessary for their survival in nature, which makes them integral aspects of welfare. Studies in sheep have shown that they are able to discriminate between different colours (Morton and Avanzo 2011), recognise and remember faces of different people (Kendrick 1991) and other sheep (Kendrick et al. 2001), and adapt their behaviour to other sheep as part of a social hierarchy.

Farm animals could use these cognitive abilities when maintained in a variable environment. The availability of pasture or paddocks may be a source of variable environments. The intensive production environment, however, particularly those for pigs and poultry, would certainly not provide this opportunity for the animals.

\subsubsection{Conclusions and Perspectives}

Farm animals' conditions have significantly changed over the last 50 years. These have included positive effects such as more adequate quality of feed and better health management. But there have also been negative impacts such as those brought about by a one-sided ambition to increase profitability. This has led to farms with increased concentrations of animals, and with practices catered towards meeting this goal rather than maintaining animal health and welfare. In one respect, farm animals are increasingly invisible and instead seen as numbers, amounts, units and subjects for trade. Yet, there is also a movement that recognises farm animals as living sentient beings that should be treated with dignity and fairness. The five freedoms for animals provided the first step in recognising, and improving, animal health and welfare. It is our opinion that Nussbaum's framework of capabilities can now act as the much needed next step in providing a strong framework to elevate the lives of farm animals. Where the five freedoms were more based in principle, the capabilities approach supplies practical goals with clear direction in fulfilling them. The capabilities approach has the added advantage of being able to be under- 
stood within the same framework as human capabilities and may act as a universal grid for justice for animals and for those people working with them. Many of the capabilities are clearly better fulfilled in organic husbandry, but there is still definite room for improvement, specifically pertaining to the capacities of bodily health and integrity. We should thus be mindful that the increasing organic production continues to build upon principles that emphasize good animal health and welfare, and are not based on the goals and practices that resemble conventional animal husbandry. The capabilities approach can provide a good point of reference in ensuring the ethical development of future farming.

Acknowledgments Caroline Chylinski is a grateful recipient of a EU Marie-Curie PhD grant, "NematodeSystemHealth". Several sets of data presented here were obtained from research funded by the French Alteravi and ANR Pan, as well as the EU Aniplan programmes. Discussions with Nicolas Delon (Paris 1-Sorbonne) on Martha Nussbaum's framework of capabilities were enjoyable and useful for the present review. Mette Vaarst thanks the partners in the ANIPLAN project as well as the Danish partners who contributed to many research and development projects for having shared their knowledge and insight.

\section{References}

Anand P, Hunter G, Smith R (2005) Capabilities and well-being: evidence based on the SenNussbaum approach to welfare. Soc Indic Res 74:9-55

Bennedsgaard TW, Klaas IC, Vaarst M (2010) Reducing use of antimicrobials - experiences from an intervention study in organic dairy herds in Denmark. Livest Sci 131:183-192. doi: 10.1016/j.livsci.2010.03.018

Benoit M, Laignel G (2009) Performances techniques et économiques en élevage biologique d'ovins viande: observation en réseau d'élevage et fermes expérimentales. INRA Prod Anim 22:197-206

Berg C (2001) Health and welfare in organic poultry production. Acta Vet. Scan Supp 95:37-45

Brinkmann J, March S, Winckler C (2012) 'Stable Schools' to promote animal health in organic dairy farming - first results of a pilot study in Germany. Agr Forest Res, Special Issue No. 362 (Braunschweig 2012). http://literatur.vti.bund.de/digbib_extern/dn050757.pdf

Cabaret J (1986) 156 plantes pour soigner les animaux. Phytothérapie vétérinaire. Ed. Point vétérinaire, Maisons-Alfort, France, p 192

Cabaret J, Benoit M, Laignel G, Nicourt C (2012) Health advisors in organic meet sheep farms: the role of the veterinarians. Open Vet Sci J 5:7-11

Farm Animal Welfare Council (2012). www.defra.gov.uk/fawc. Accessed 20 Feb 2012

Ginane C, Dumont B (2011) Do sheep (Ovis aries) categorize plant species according to botanical family? Anim Cogn 14:369-376

Giudici C, Aumont G, Mahieu M, Saulai M, Cabaret J (1999) Changes in gastro-intestinal helminth species diversity in lambs under mixed grazing on irrigated pastures in the tropics (French West Indies). Vet Res 30:573-581

Guémené D, Germain K, Aubert C, Bouvarel I, Cabaret J, Chapuis H, Corson M, Jondreville C, Juin H, Lessire M, Lubac S, Magdelaine P, Leroyer J (2009) Les productions avicoles biologiques en France: état des lieux, verrous, atouts et perspectives. INRA Prod Anim 22:161-178

Hovi M, Gray D, Vaarst M, Striezel A, Walkenhorst M, Roderick S (2004) Promoting health and welfare through planning. In: Vaarst M, Roderick S, Lund V, Lockeretz W (eds) Animal health and welfare in agriculture. Cabi Publishing, Wallingford, pp 253-277 
IFOAM (Internal Federation of Organic Movements) (2012). http://www.ifoam.org/about_ifoam/ principles/index.html. Accessed 20 Feb 2012

Ivemeyer S, Smolders G, Brinkmann J, Gratzer E, Hansen B, Henriksen BIF, Huber J, Leeb C, March S, Mejdell C, Nicholas P, Roderick S, Stoger E, Vaarst M, Whistance LK, Winckler C, Walkenhorst M (2012) Impact of animal health and welfare planning on medicine use, herd health and production in European organic dairy farms. Livest Sci 145:63-72. doi: 10.1016/j. livsci.2011.12.023

Jeangène Vilmer JB (2008) Ethique animale. PUF, Paris, p 304

Kaltoft P (1999) Values about nature in organic farming practice and knowledge. Sociol Ruralis 39:39-53

Kendrick KM (1991) How the sheep's brain controls the visual recognition of animals and humans. J Anim Sci 69:5008-5016

Kendrick KM, da Costa AP, Leigh AE, Hinton MR, Peirce JW (2001) Sheep don't forget a face. Nature 414:165-166

Lund V, Anthony R, Röcklingsberg H (2004) The ethical contract as a tool in organic animal husbandry. J Agr Env Ethics 17:23-49

Magdelaine P (2006) Marché Français et Européen des œufs de consommation. Journée Nationale des professionnels de la pondeuse et de l'œuf de consommation. 5 Décembre, Ploufragan, France, $\mathrm{p} 12$

Menke C, Waiblinger S, Studnitz M, Bestman M (2004) Mutilations in organic husbandry dilemmas involving animal welfare, humans and environmental protection. In: Vaarst M, Roderick S, Lund V, Lockeretz W (eds) Animal health and welfare in agriculture. Cabi Publishing, Wallingford, pp 163-188

Morton AJ, Avanzo L (2011) Executive decision-making in the domestic sheep. PLOS One 6:1-8

Nicholas P, Vaarst M (2011) From plan to planning. In: Vaarst M, Roderick (eds) The process of minimising medicine use through dialogue based animal health and welfare planning: workshop report - core organic project nr.: 1903-ANIPLAN. 2011, 22-25. http://orgprints. org/18404/1/18404.pdf. Accessed 18 Nov 2013

Nicourt C, Cabaret J (2014) Animal healthcare strategies in organic and conventional farming. In: Bellon S, Penvern S (eds) Organic farming, prototype for sustainable agricultures. Springer, Chap. 9, pp 171-179

Nowak R, Keller M, Levy F (2011) Mother-young relationships in sheep: a model for a multidisciplinary approach of the study of attachment in mammals. J Neuroendocrinol 23:1042-1053

Nussbaum MC (2001) Symposium on Amartya Sen's Philosophy: 5. adaptive preferences and women's options. Econ Philos 17:67-88

Nussbaum MC (2006a) The moral status of animal. Chronical of higher education, February 3:1-6

Nussbaum MC (2006b) Frontiers of justice: disability, nationality, species membership. The Belknap Press, Cambridge

Piccardi M, Capitaine Funes A, Bo GA, Balzarini M (2011) Impacto del nivel de produccion, estacion de parto y el tipo de servicio sobre la tasa de prenez acumulada a 100 dias en vacas lecheras en la Argentina. AgriScientia 28:127-135

Porcher J (2003) La mort n'est pas notre métier (Death is not our job). Editions de l'Aube

Porcher J (2014) Breaking with animal production paradigm: a major issue for organic animal husbandry. In: Bellon S, Penvern S (eds) Organic farming, prototype for sustainable agricultures. Springer, Chap. 15, pp 279-293

Porcher J, Daru E (2005) Concevoir des alternatives à l'organisation industrielle du travail. Un camion pour le transport et l'abattage des animaux (Designing alternatives to industrial organization of work. A truck for transport and slaughter of animals in farm). FaçSADe (INRASAD), n'2005-23. http://www.inra.fr/sciences_action_developpement/publications/facsade/ concevoir_des_alternatives_a_1_organisation_industrielle_du_travail_en_elevage. Accessed 18 Nov 2013

Prunier A (2010) Caractéristiques des élevages enquêtés dans le projet Corepig. Prévention de la santé des porcs biologiques. Actes du colloque Corepig, 14 décembre, Rennes. http://www. 
interbiobretagne.asso.fr/upload/File/Recherche/Elevage/Corepig/Actes_Corepig_2010.pdf. Accessed 24 Feb 2012

Pryce JE, Conington J, Sørensen P, Kelly HRC, Ryhdmer L (2004) Breeding strategies for organic livestock. In: Vaarst M, Roderick S, Lund V, Lockeretz W (eds) Animal health and welfare in agriculture, Cabi Publishing, Wallingford, pp 357-388

Sormunen-Cristian R, Manninen M, Jauhiainen L, Oksanen A (2008) Effect of mixed grazing of suckler cows and lambs on faecal egg counts and animal performance. In: Hopkins A, Gustafsson $\mathrm{T}$, Bertilsson $\mathrm{J}$ et al (eds) Biodiversity and animal feed: future challenges for grassland production. pp 861-863. Proceedings of the 22nd General Meeting of the European Grassland Federation, Uppsala 9-12 June 2008

Sanga U, Provenza FD, Villalba JJ (2011) Transmission of self-medicative behaviour from mother to offspring in sheep. Anim Behav 82:219-227

Sato K, Bartlett PC, Erskine RJ, Kaneene JB (2005) A comparison of production and management between Wisconsin organic and conventional dairy herds. Livest Prod Sci 93:105-115

Sen A (2005) Human rights and capabilities. J Hum Dev 6:151-166

Singer P (1975) Animal liberation. A new ethics for our treatment of animals. Random House, New York

Tague IH (2010) Companions, servants, or slaves? Considering animals in eighteenth-century Britain. Stud Eighteenth Cent 39:111-130

Thamsborg SM, Roderick S, Sundrum A (2004) Animal health and diseases in organic farming: an overview. In: Vaarst M, Roderick S, Lund V, Lockeretz W (eds) Animal health and welfare in agriculture, Cabi Publishing, Wallingford, pp 227-252

Thorhalsdottir AG, Provenza FD, Balph DF (1987) Food aversion learning in lambs with or without a mother: discrimination, novelty and persistence. Appl Anim Behav Sci 18:327-340

Vaarst M, Alroe HF (2012) Concepts of animal health and welfare in organic livestock systems. J Agr Environ Ethic 25(3):333-347

Vaarst M, Nissen TB, Østergaard S, Klaas IC, Bennedsgaard TW, Christensen J (2007) Danish stable schools for experiential common learning in groups of organic dairy farmers. J Dairy Sci 90:2543-2554

Vaarst M, Martini A, Bennedsgaard T, Hektoen L (2004) Approaches to the treatment of diseased animals. In: Vaarst M, Roderick S, Lund V, Lockeretz W (eds) Animal health and welfare in agriculture. Cabi Publishing, Wallingford, pp 279-307

Vaarst M, Smolders G, Leeb C, Henriksen BIF, Roderick S, Walkenhorst M, Winckler C, Gratzer E, Stöger E., Brinkmann J, March S, Ivemeyer S, Mejdel C, Nicholas P, Whistance LK (2011) Education and advisor systems related to dairy organic farming in the participating countries In: Vaarst M, Roderick (eds) The process of minimising medicine use through dialogue based animal health and welfare planning: Workshop report — Core Organic project nr.: 1903-ANIPLAN. 2011, 53-63. http://orgprints.org/18404/1/18404.pdf

Vaarst M, Winckler C, Roderick S, Smolders G, Ivemeyer S, Brinkmann J, Mejdell CM, Whistance LK, Nicholas P, Walkenhorst M, Leeb C, March S, Henriksen BIF, Stöger E, Gratzer E, Hansen B, Huber J (2012) Animal health and welfare planning in organic dairy cattle farms. Open Vet Sci J 5:19-25

Verhoog H, Lund V, Alroe HJ (2004) Animal welfare, ethics and organic farming. In: Vaarst M, Roderick M, Lund V, Lockeretz W (eds) Animal health and welfare in Organic agriculture. CABI Publishing, Wallingford, p 73-94

Veissier I, Botreau R, Perny P (2012) Multicriteria evaluation applied to farm animal welfare: difficulties and solutions from the Welfare Quality (R) project. Prod Anim 23:269-283

Veysset P, Bécherel F, Bébin D (2009) Elevage biologique de bovins allaitants dans le Massif Central: résultats technico-économiques et identifications des principaux verrous. INRA Prod Anim 22:189-196

Waiblinger S, Baumgartner J, Kiley-Wothington M, Niebuhr K (2004) Applied ethology: the basis for improved animal welfare in organic farming. In: Vaarst M, Roderick M, Lund V, Lockeretz W (eds) Animal health and welfare in organic agriculture. CABI Publishing, Wallingford, pp 117-161 
Waiblinger S, Boivin X, Pedersen V, Tosi MV, Janczak AM, Visser EK, Jone RB (2006) Assessing the human-animal relationship in farmed species: A critical review. Appl Anim Behav Sci 101:185-242

Warren MA (1997) Moral status: obligations to persons and other living things. Oxford University Press, Oxford, p 274

Wynn SG, Wolpe PR (2005) The majority view of ethics and professionalism in alternative medicine. JAVMA 226:516-520

Zollitsch W, Kristensen T, Krutzinna C, MacNaeihde F, Younie D (2004) Feeding for health and welfare: the challenge of formulating well-balanced rations in organic livestock production. In: Vaarst M, Roderick S, Lund V, Lockeretz W (eds) Animal health and welfare in agriculture. Cabi Publishing, Wallingford, pp 329-356 